\title{
Wilson's disease: a review of treatment options with a focus on zinc therapy
}

This article was published in the following Dove Press journal:

Orphan Drugs: Research and Reviews

10 October 2012

Number of times this article has been viewed

J Hui'

NL Tang ${ }^{2}$

'Department of Pediatrics,

${ }^{2}$ Department of Chemical Pathology,

Prince of Wales Hospital, The Chinese

University of Hong Kong, Shatin,

Hong Kong
Correspondence: Joannie Hui 6/F Clinical Sciences Building,

Department of Pediatrics, Prince of Wales Hospital, The Chinese University of Hong Kong, Shatin, Hong Kong Special Administrative Region, China

Tel +85226322982

Fax +85226360020

Email joanniehui@cuhk.edu.hk
Abstract: Wilson's disease, an inherited disorder of copper metabolism, is well known for its remarkable heterogeneous clinical presentation and variable organ involvement. Since its first introduction almost five decades ago, zinc - with its relative lack of side effects and safety profile - has gained a lot of attention and favor over other therapeutic agents for the treatment of Wilson's disease. Traditional chelating agents like D-penicillamine and trientine, although proven to be efficacious, compared less favorably to zinc because of their long list of potential side effects. The medical literature regarding the use of zinc generally supports its primary role in the treatment of presymptomatic/asymptomatic, pediatric, and pregnant patients. However, for symptomatic patients - especially the symptomatic hepatic patients, long-term follow-up studies concluded that zinc is less effective than chelating agents in preventing hepatic deterioration. Other treatment concepts like combination therapy using zinc in conjunction with a chelating agent or sequential treatment with initial chelating agents followed by zinc have been tried with variable success. Rigorously designed studies and safety data on these newer treatment concepts are not yet available. Independent of the chosen medical regimen, nonadherence or discontinuation with noncompliance is the biggest threat adversely affecting the long-term outcome in all treated patients with Wilson's disease. Close monitoring as well as long-term follow-up for the development of new neurologic or hepatic symptoms are essential for all patients, irrespective of how long they have been on treatment and whether treatment has remained static for years. In this paper, the authors will discuss the current opinion and role of zinc in the treatment of various manifestations and different stages of Wilson's disease.

Keywords: Wilson's disease, treatment, zinc

\section{Introduction}

Wilson's disease (Mendelian Inheritance in Man \#277900) is an autosomal recessive disorder of copper metabolism resulting in systemic copper accumulation and multiorgan damage, particularly of the liver and brain. Also known as hepatolenticular degeneration, the disease was first described by Kinnier Wilson in 1912. ${ }^{1}$ Eight decades later, in 1993, the genetic defect of this disease was identified to be due to mutation of the ATP7B gene, ${ }^{2}$ which is located on chromosome 13 . The gene $(A T P 7 B)$ encodes a transmembrane protein adenosine triphosphatase (ATP7B), which functions as a copper-dependent P-type adenosine triphosphatase. The ATP7B transporter has dual synthetic and excretory roles: functioning in the transport of copper into the trans-Golgi compartment for incorporation into the plasma protein ceruloplasmin and into the bile for excretion of excess stores. Defective ATP7B function results in hepatic copper accumulation, which leads to the hepatic and neurological features of Wilson's disease. 
The classic presentation of Wilson's disease comprises of the trio of liver disease plus neurological and ophthalmological involvement. Previously, the diagnosis of Wilson's disease was established when at least two out of the three following Sternlieb criteria were present: (1) serum ceruloplasmin level $<20 \mathrm{mg} / \mathrm{dL}$, (2) presence of Kayser-Fleischer rings by slit lamp examination, and/or (3) hepatic copper content $>250 \mathrm{mg} / \mathrm{g}$ dry weight liver tissue in the presence of hepatic and/or neurological clinical manifestations consistent with Wilson's disease. ${ }^{3}$ However, for presymptomatic and pediatric patients who may not have such substantial copper accumulation in tissues, this diagnostic criterion may not be applicable. In the present molecular genomic era, which started in 1993 when the first molecular diagnosis of Wilson's disease was carried out, patients can often be diagnosed at an earlier stage by identifying genetic mutations before they develop overt signs or symptoms of the disease. This diagnostic approach is especially important for diseases where early therapeutic intervention is available to prevent irreversible damage, and Wilson's disease is one such disease prototype.

Knowledge of the clinical presentations and treatment of this disease are important to physicians practicing in different specialties. With the variable organ and often multisystem involvement, Wilson's disease patients may be presenting themselves to specialists in gastroenterology, hepatology, neurology, psychiatry, and pediatrics. The diagnosis may easily be overlooked if it was not considered a diagnostic possibility and followed by the necessary biochemical investigations. Establishing an early diagnosis of Wilson's disease is of utmost importance and one of the key steps in altering its outcome, preventing or ameliorating potential lethal complications.

Without treatment, Wilson's disease causes progressive liver disease, neurological deterioration, and death. When diagnosed early, it is a treatable condition with good outcome. There are several chelating agents and zinc salts available for the medical therapy of Wilson's disease. D-penicillamine and trientine are two of the chelator agents employed with established efficacy. Yet they also have potential significant side effects and complications. Over the last five decades, newer and less toxic substitutes with zinc therapy have emerged as a popular treatment option for Wilson's disease patients, especially those with a mild disease and low body copper load like the presymptomatic or pediatric patients. ${ }^{4,5}$

In this paper, the authors will discuss the current opinion and role of zinc in the treatment of various manifestations and different stages of Wilson's disease. On the whole, zinc is the mainstay of treatment for the presymptomatic, asymptomatic, and pediatric patients as well as maintenance therapy for those whose disease has been stabilized by previous chelation therapy.

\section{Overview of D-penicillamine, Trientine, and Tetrathiomolybdate}

As mentioned above, Wilson's disease is a condition that is mainly treated by medical means. The objective of therapy is to reduce copper accumulation, either by enhancing its urinary excretion or by reducing its intestinal absorption. The three Food and Drug Administration-approved drugs for the treatment of Wilson's disease are D-penicillamine, trientine, and zinc acetate.

\section{D-penicillamine}

D-penicillamine was introduced as the first oral agent for treating Wilson's disease by Walshe in $1956 .{ }^{6}$ It is a metabolic byproduct of penicillin (dimethyl cysteine) that avidly chelates copper and holds it until the complexed copper is excreted in the urine. Additional action includes inducing metallothionein, ${ }^{7}$ a cysteine-rich protein that is an endogenous chelator of metals. Total bioavailability after oral administration is $40 \%-70 \%$. More than $80 \%$ of D-penicillamine excretion is in urine together with the chelated copper. ${ }^{8}$ The clinical benefit of D-penicillamine in Wilson's disease is well documented. ${ }^{5}$ For patients with symptomatic liver disease, the time for evidence of recovery of synthetic function and improvement in clinical signs such as jaundice and ascites is typically during the first 2-6 months of treatment. Further recovery may occur during the first year of treatment. In patients with neurologic Wilson's disease, improvement of symptoms is slower and may be observed after 3 years. ${ }^{9}$ The use of D-penicillamine is associated with numerous side effects. Severe side effects requiring the drug to be discontinued occur in approximately $30 \%$ of patients. ${ }^{4,10}$ Early sensitivity reactions marked by fever and cutaneous eruptions, lymphadenopathy, neutropenia or thrombocytopenia, and proteinuria may occur during the first 1-3 weeks. ${ }^{11}$ Late reactions include nephrotoxicity with proteinuria, a lupus-like syndrome marked by hematuria, proteinuria, and positive antinuclear antibody. Significant bone marrow toxicity includes severe thrombocytopenia or total aplasia. Skin complications have also been observed with long-term use of D-penicillamine, including progeriatric changes, elastosis perforans serpiginosa, ${ }^{12}$ and aphthous stomatitis. Furthermore, D-penicillamine can affect pyridoxine metabolism, and this vitamin (vitamin B6) is 
recommended to be added for children, pregnant women, and patients with malnutrition or during an intercurrent illness. $^{13}$

Other than potential side effects as listed above, the other major concern with the use of D-penicillamine is that worsening of neurologic symptoms has been reported in $10 \%-50 \%$ of patients during the initial phase of treatment. Walshe and Yealland noted this in 22\% of 137 Wilson's disease patients treated with D-penicillamine. ${ }^{14}$ Brewer reported the same observation in $52 \%$ of 25 patients in a retrospective study. ${ }^{9} \mathrm{He}$ also observed that $50 \%$ of those in whom neurological deterioration occurred upon initiation of therapy did not fully recover to their baseline level of functioning. The side effects together with the risk of initial neurological deterioration have led to other agents being considered more suitable first-line treatment for Wilson's disease. ${ }^{9}{ }^{15}$ While some investigators may still continue using D-penicillamine but with lower initiating doses, others recommend safer medications like trientine, zinc, or tetrathiomolybdate for treatment induction. Some investigators like Brewer advocated D-penicillamine not be used at all in the treatment of Wilson's disease, except possibly in the patient with acute, fulminant hepatic failure while awaiting liver transplantation. ${ }^{16}$

\section{Trientine (triethylenetetramine dihydrochloride)}

Trientine was introduced in 1969 as an alternative to D-penicillamine, ${ }^{17}$ especially for those patients who are intolerant of D-penicillamine. It functions as a chelator with a polyamine-like structure chemically distinct from D-penicillamine, and competes for copper bound to albumin and does not enter the liver. ${ }^{18}$ Thus, trientine may be mobilizing a different pool of body copper from D-penicillamine. Like D-penicillamine, trientine promotes copper excretion by the kidneys and is effective for treating Wilson's disease. Together with a better safety profile, trientine is becoming recognized as an effective initial treatment for Wilson's disease, ${ }^{15,19-21}$ even with decompensated liver disease at the outset. ${ }^{22,23}$ Askari et al studied nine adults with severe liver disease identified over a 10 -year period who received initial treatment with trientine and zinc. ${ }^{24}$ Only one patient had hepatic encephalopathy. In the eight patients receiving trientine and zinc, the combination was given for at least 4 months and then maintenance zinc treatment was used. Over the first 12 months of treatment, prothrombin time and raised bilirubin and albumin concentrations returned to normal, and ascites disappeared. Benefit was maintained over 12 months to 14 years of follow-up. Side effects of trientine include a reversible sideroblastic anemia, ${ }^{25}$ which may be a consequence of overtreatment, and resultant copper deficiency. Lupus-like reactions have also been reported in some Wilson's disease patients treated with trientine, ${ }^{26}$ but it is not certain whether the same may have arisen as a result of previous D-penicillamine treatment. ${ }^{27}$ As evidence grows for better efficacy and fewer side-effects, trientine is now regarded as an accepted alternative to D-penicillamine for initial treatment of Wilson's disease. It is especially indicated in patients who are intolerant of D-penicillamine or have clinical features indicating potential intolerance (history of renal disease of any sort, congestive splenomegaly causing severe thrombocytopenia, and autoimmune tendency). Less neurologic deterioration when compared with D-penicillamine has led to its increasing use as a first-line treatment for those presenting with neurological dysfunction. ${ }^{15,27}$

\section{Tetrathiomolybdate}

Tetrathiomolybdate was first tested for the treatment of Wilson's disease in 1984. It is a strong decoppering agent that has two mechanisms of action. ${ }^{28}$ First, it complexes copper in the intestinal lumen and prevents its absorption. Second it complexes copper with albumin in the blood once it has been absorbed and makes the copper unavailable for cellular uptake. The efficacy of tetrathiomolybdate has mainly been tested in patients with neurologic Wilson's disease showing less neurological deterioration associated with its use than D-penicillamine..$^{29,30}$ A randomized, double-blind, controlled, two-arm study on 48 Wilson's disease patients with a neurological presentation was performed. Patients were treated with either trientine or tetrathiomolybdate for 8 weeks. ${ }^{30}$ Fewer patients on tetrathiomolybdate experienced a neurological deterioration than those on trientine. ${ }^{30}$ The control of free copper with tetrathiomolybdate as initial anticopper treatment in neurologically presenting Wilson's disease patients had also been prospectively studied. ${ }^{31}$ Results showed that tetrathiomolybdate had very strong control of free copper levels and achieved this better than trientine. ${ }^{31}$ About $15 \%$ of patients on tetrathiomolybdate experienced mild side effects, which included bone marrow toxicity (anemia, thrombocytopenia, and neutropenia) or rising aminotransferase levels. ${ }^{32,33}$ Both effects were transient and responded to suspension of the drug. Based on the above efficacy results, tetrathiomolybdate was proposed as an initial treatment for Wilson's disease patients with neurological signs and symptoms. Yet its use remains restricted as it is still not commercially available in the United 
States or the European Union. Further clinical experience on tetrathiomolybdate remains limited.

\section{Zinc}

\section{History of zinc and its mechanism of action}

Zinc was first utilized in veterinary medicine as a treatment for copper accumulation in sheep by Dick in $1954 .{ }^{34}$ Borrowing from this experience, the first human use of zinc for patients with Wilson's disease was conducted by the Dutch investigator Schouwink in $1961 .^{35}$ Zinc's mechanism of action is different from that of D-penicillamine and trientine. Zinc interferes with the uptake of copper from the gastrointestinal tract. It induces enterocyte metallothionein, a cysteine-rich protein that is an endogenous chelator of metals. Metallothionein has greater affinity for copper than for zinc and thus preferentially binds copper present in the enterocyte and inhibits its entry into the portal circulation. Once bound, copper is not absorbed but is lost into the fecal contents as enterocytes are shed in normal turnover. ${ }^{36}$ As copper also enters the gastrointestinal tract from saliva and gastric secretions, zinc treatment can generate a negative balance for copper and thereby remove stored copper. ${ }^{37}$ Zinc may also act by inducing levels of hepatocellular metallotheionein. $.^{38}-40$ Over the last three decades, George Brewer from the University of Michigan (Ann Arbor, MI) published extensively on the use of zinc for the treatment of Wilson's disease in various clinical settings. ${ }^{36,37,41-50}$ His group demonstrated that zinc can cause a negative copper balance, controls urine and plasma copper levels, removes stored copper, and protects the liver at least in part by inducing expression of hepatic metallothionein. ${ }^{37,38,46-50}$ They also performed pharmacokinetic studies of copper absorption of patients treated with zinc, demonstrating that when used in multiple daily doses and not as a single daily dose, zinc effectively blocked copper absorption. ${ }^{38}$ This blockage of copper absorption eventually reduced the body's copper burden over time in most patients. ${ }^{45,51,52}$

In addition to the demonstrated efficacy, zinc also has a much better safety profile than the chelating agents D-penicillamine and trientine. This has led to the recommendation of zinc being the treatment of choice for maintenance therapy of adult and pediatric Wilson's disease patients, ${ }^{43}$ presymptomatic patients from the outset, ${ }^{47}$ and pregnancy therapy as well. ${ }^{44}$ Zinc acetate was approved by the United States Food and Drug Administration in 1997. Reports of large series of Wilson's disease patients treated with zinc confirmed good clinical efficacy, ${ }^{42,53}$ with favorable reports in children as well as in adults. ${ }^{54,55}$ Zinc has also been extensively used in the Netherlands by Hoogenraad et al and also in Poland. .,53,56-58 $^{-5}$

\section{Dose and administration of zinc}

The recommended dose in milligrams of elemental zinc is $150 \mathrm{mg} /$ day in three divided doses for larger children and adults. ${ }^{59}$ Compliance with the three times per day dosage may be problematic, and it has to be taken at least twice daily to be effective. ${ }^{42}$ For smaller children ( $<50 \mathrm{~kg}$ in body weight), the dose is $75 \mathrm{mg} /$ day in three divided doses; ${ }^{43}$ the dose is not well defined for children under 5 years of age. In a cohort series with 22 pediatric patients, Marcellini et al used the following regimen: zinc sulfate $25 \mathrm{mg}$ elemental twice a day until the age of 6 years, $25 \mathrm{mg}$ three times a day between the ages of 7 years and 16 years or until the child attained a body weight of $57 \mathrm{~kg}$, and $50 \mathrm{mg}$ three times a day thereafter. ${ }^{54}$ Taking zinc with food interferes with zinc absorption and effectiveness of treatment. ${ }^{60}$ Thus zinc is recommended to be taken 1 hour before or after meals which further compromises compliance. Some may use dose adjustments to compensate for this effect, hoping that taking zinc around meal time may ensure better compliance.

\section{Side effects of zinc}

Zinc has very few side effects. Gastric irritation is the most common problem. Hepatic deterioration has been occasionally reported when zinc was commenced and was fatal in one case. ${ }^{61,62}$ Elevations in serum lipase and/or amylase may occur without clinical or radiologic evidence of pancreatitis. ${ }^{63}$

\section{Use of zinc}

Because of its efficacy as well as the relative safety and freedom from major side effects with long-term use, zinc has been well accepted as the optimal choice of treatment for patients with presymptomatic or asymptomatic Wilson's disease. However, its role for the treatment of symptomatic patients is less clear cut. Despite individual case reports and larger case series with patients effectively treated only with zinc, $, 5,33,42,53,64$ many remain skeptical and would only consider zinc as an adjunctive therapy for the initial treatment of symptomatic patients especially those with a high copper load. Recent studies with long-term follow-up data supported this view and recommended careful monitoring and followup for potential deterioration particularly in the group of symptomatic patients whose disease may have been better controlled by chelating agents rather than zinc. ${ }^{65,66}$

A recent study by Weiss et al reported the long-term treatment outcome and reasons for discontinuation of medical therapy in 288 Wilson's disease patients from two tertiary European treatment centers ${ }^{65}$ In this large series, 
patients were followed up for a median of 17 years. The overall discontinuation of therapy was significantly more frequent in those receiving zinc monotherapy or combination therapy than chelation therapy. Hepatic treatment failure, defined as an increase in the activity of liver enzymes more than two-fold the upper limit of normal or $>100 \%$ of baseline with an increase in urinary copper excretion, occurred more often from zinc therapy (14/88 treatments) than from chelation therapy $(4 / 313$ treatments; $P<0.001)$. Those patients who did not respond to zinc therapy showed hepatic improvement after reintroduction of a chelating agent. This was followed by normalization of elevated liver enzyme levels in all nonresponders to zinc. The authors concluded that while treatment with chelating agents or zinc salt were effective in most patients with Wilson's disease, chelating agents were better at preventing hepatic deterioration. They stressed the importance of identifying patients who did not respond to zinc therapy and may need a chelating agent to be added to their therapeutic regimen.

Another recent study on exclusive zinc monotherapy with long term follow up was published by Linn et al ${ }^{66}$ The treatment outcome of 17 symptomatic Wilson's disease patients treated exclusively with zinc was reported after a median follow up of 14 years. Presentation among these patients was exclusively hepatic, exclusively neurologic, and combined in seven, five, and five patients, respectively. Nine out of ten neurologic patients showed remarkable improvement in their neurologic symptoms and signs. Twelve patients had preexisting hepatic disease. At baseline, two of the 12 patients with hepatic disease exhibited decompensated cirrhosis, five exhibited compensated cirrhosis, and five had less severe disease. Both patients with decompensated cirrhosis improved to a compensated state after initiation of therapy. Two of the five patients with initial compensated cirrhosis progressed to a decompensated state, and three remained stable. Three of the five patients with moderate or mild liver disease remained stable and two improved. The authors concluded that the outcome of exclusive zinc therapy is generally good in cases of neurologic disease. A less satisfactory outcome in hepatic disease may relate to less efficient decoppering.

\section{Recommendations for the treatment of Wilson's disease according to specific clinical situations}

The fact that virtually all data on treatment options of Wilson's disease are from clinical series rather than randomized studies makes definitive treatment recommendations difficult. ${ }^{9,15,59}$ Important variables confounding outcome include the clinical phase and pattern of disease when treatment starts and patients' compliance with treatment. The choice of which of the three (D-penicillamine, trientine, and zinc) readily available therapeutic options depends largely on the clinical setting of each individual patient. While all three drugs have proven clinical efficacy in different clinical contexts, another important consideration factor on which drug to use is the relative side effects especially considering the lifelong use for most patients. Clinical treatment guidelines by Roberts and Schilsky, (approved by the American Association for the Study of Liver Diseases), and the European Association for the Study of the Liver guidelines proposed treatment for individual Wilson's disease patients according to the following clinical contexts: $:^{27,59}$

1. Whether patients are symptomatic or asymptomatic/ presymptomatic

2. Whether symptomatic patients have predominant neurological or hepatic manifestation: (a) mildly affected with elevation of liver enzymes or established cirrhosis, (b) decompensated cirrhosis, or (c) acute liver failure

3. Whether patients are in the acute or maintenance phase of treatment

4. Pregnant patients

5. Pediatric patients.

\section{Asymptomatic/presymptomatic patients}

Presymptomatic patients are often diagnosed during a family workup. Siblings of a diagnosed patient are at a $25 \%$ risk of having the disease. Some patients may occasionally be diagnosed because of a chance observation of KayserFleischer rings. These patients are recommended to be treated prophylactically to prevent disease symptoms or progression with either a chelating agent (D-penicillamine or trientine) or zinc. ${ }^{11,47,67}$ Roberts and Schilsky recommended only zinc for presymptomatic children under the age of 3 years. ${ }^{59}$

\section{Neurologically presenting patients}

Treatment of neurologically presenting Wilson's disease patients is complicated by the fact that chelating agents like D-penicillamine and trientine may actually cause harm and worsen the neurologic status of these patients. ${ }^{9}$ Because of this potential risk, some authors suggested D-penicillamine not to be used at all in neurologically presenting patients. ${ }^{41}$ As the mechanism of action of trientine is quite similar to D-penicillamine, it also shares the risk of initial neurological worsening although not as often as with D-penicillamine. 
Encouraging clinical results have been demonstrated with tetrathiomolybdate for the initial treatment of the neurologically presenting patients. Yet it remains an experimental therapy and is not commercially available.

Zinc acts in a different manner from penicillamine and trientine by blocking further copper absorption rather than mobilizing copper already in the body. Thus it is less likely to worsen the neurological disease by virtue of its anticopper action and has been successfully used as a monotherapy for neurologically presenting Wilson's disease patients. Linn's study on zinc as an exclusive monotherapy on 17 symptomatic Wilson's disease patients showed that the neurologic disease patients had a more satisfactory outcome compared with the hepatic disease patients. ${ }^{66}$ However, zinc is rather slow acting and may take 4-6 months to stop ongoing copper toxicity. There is thus a potential risk that the disease may progress due to its own natural history if patients are just on zinc alone. ${ }^{41}$

There is as yet no unequivocal clear consensus for treating the individual with neurologic or psychiatric dysfunction due to Wilson's disease. Current recommendations remain initiating therapy with a chelating agent, either D-penicillamine or trientine, with the latter gaining increasing favor. Although zinc is recommended by some investigators for initiation of therapy, others reserve its use for maintenance therapy following initial employment of a chelating agent..$^{27,59}$

\section{Patients presenting with liver disease Liver presentation with transaminase elevations and/or cirrhosis without significant hepatic failure}

This group of hepatic Wilson's disease patients who do not have evidence of hepatic decompensation in terms of low albumin, elevated bilirubin, and prolonged prothrombin time are recommended the same treatment as those in the maintenance phase of treatment (see below).

\section{Decompensated cirrhosis}

Patients who present with decompensated chronic liver disease, typically with hypoalbuminemia, prominent coagulopathy, and ascites but no encephalopathy, have been treated successfully with either D-penicillamine or trientine plus zinc. ${ }^{23,24,69}$ The rationale for the addition of zinc to the treatment regimen is that it will induce hepatic metallothionein, which will then bind up loosely bound and potentially toxic copper in the liver, tending to decrease further damage while the chelating agent gets rid of the excessive copper. The two types of treatment must be temporally dispersed throughout the day to avoid having the chelator bind the zinc and thus potentially cancel the efficacy of either modality. Combination therapy was recommended until liver function tests improve (usually 4-6 months) and then maintenance therapy begins with either one of the medication. This type of combination treatment is still being considered as investigational, ${ }^{45,59}$ and those patients who fail this intensive induction regimen may need to be treated by liver transplantation.

\section{Acute liver failure}

Patients with acute liver failure due to Wilson's disease should be treated immediately with liver transplantation which may be lifesaving. ${ }^{59,68,69}$ To help determine which patients with acute hepatic presentations may not survive without liver transplantation, Nazer et al developed a prognostic score with components including serum bilirubin, serum aspartate aminotransferase, and prolongation of prothrombin time. In their series, patients with a score of seven or greater did not survive. ${ }^{70}$ Similar scoring systems have also been devised for adults with acute liver failure due to Wilson's disease. ${ }^{71}$ Success with combination therapy trientine plus zinc has been reported in patients with a Nazer score as high as nine. ${ }^{24}$ Thus a trial of such combination therapy is recommended especially while awaiting the workup for a liver transplant.

\section{Maintenance therapy}

After adequate treatment with a chelator, stable patients may be continued on a lower dosage of the chelating agent or shifted to zinc. ${ }^{59}$ The types of patients who are considered under maintenance therapy include those who presented clinically with neurological/psychiatric disease or liver disease, have received initial treatment with an anticopper drug or a combination of drugs, and have had their disease well controlled. As mentioned above, presymptomatic patients and patients with hepatitis or cirrhosis but without liver failure are also considered for maintenance therapy, which is intended for the remainder of their lives with the purpose of preventing further copper toxicity. ${ }^{59}$ The transition from acute treatment to maintenance therapy usually takes place between 1-5 years after the start of acute treatment. Patients are usually clinically well with normal serum aminotransferase levels and hepatic synthetic function, nonceruloplasmin bound copper concentration in the normal range, and 24-hour urinary copper repeatedly in the range of 200-500 $\mu \mathrm{g} /$ day $\left(3-8 \mu \mathrm{mol} /\right.$ day). ${ }^{59}$ Adequate studies regarding the timing of this changeover in treatment of adult patients with hepatic Wilson's disease are not available, and 
only limited data are available for children. ${ }^{72}$ No matter how well a patient appears, treatment should never be terminated indefinitely and those who discontinue treatment altogether risk development of intractable hepatic decompensation.

\section{Pregnant patients}

Women with Wilson's disease who become pregnant are recommended to have their treatment continued throughout pregnancy. ${ }^{41,59}$ Interruption of treatment during pregnancy has resulted in acute liver failure. ${ }^{73}$ Treatment with chelating agents (both D-penicillamine and trientine) $)^{74-77}$ and zinc salts $^{44,78}$ has been associated with satisfactory outcomes for both the mother and fetus. ${ }^{79-83}$ However, there are also reported teratogenic effects with D-penicillamine and trientine in animals as well as in humans. ${ }^{84-86} \mathrm{~A}$ case series on the results of 26 pregnancies in 19 women who were on zinc therapy throughout their pregnancy reported good outcome in the mother and the fetus, except one baby had a surgically correctable heart defect and another had microcephaly. ${ }^{44}$ It is difficult to ascertain whether the frequency is any different from the rest of the population. While the dosage of zinc salts is maintained throughout pregnancy without change, ${ }^{44}$ dosages of chelating agents are recommended to be reduced to the minimum necessary especially for the last trimester so as to promote better wound healing if a cesarean section is performed. Such a dose reduction might be of the order of $25 \%-50 \%$ of the prepregnancy dose.$^{59}$ As copper deficiency is also teratogenic, control is recommended not to be too tight during pregnancy and frequent monitoring during pregnancy is necessary.

Women taking D-penicillamine are recommended not to breastfeed because the drug is excreted into breast milk and might harm the infant ${ }^{59}$ It has been established that mothers on zinc therapy do not excrete abnormal amounts of zinc in breast milk. ${ }^{87}$

\section{Pediatric patients}

Pediatric patients with Wilson's disease are usually identified through the following means. First, they may present with manifestation of the disease similar to that seen in symptomatic adult patients with obvious liver disease, a neurological movement disorder, or occasionally copper-induced behavioral abnormalities. Secondly, they may be identified through the incidental finding of an abnormality on routine screening, such as an enlarged liver or spleen on physical examination, elevated transaminases, or the finding of Kayser-Fleischer rings on eye examination. Thirdly, they may be identified through family screening after the diagnosis has been confirmed in another sibling. The latter two groups of pediatric patients are considered as being asymptomatic/ presymptomatic.

The efficacy and safety of zinc therapy in children was mainly established from its use in the asymptomatic/ presymptomatic children as well as stable children in the maintenance phase of treatment. ${ }^{43}$ Marcellini et al added further evidence and support to the use of zinc in treating young children less than 10 years of age with his study reporting the 10-year follow-up outcome of 22 zinc treated children. ${ }^{54}$ Eleven of them were younger than 6 years and 20 younger than 10 years. All patients demonstrated excellent clinical results together with improvement in hepatic histologic findings in most patients. There were no adverse effects of zinc, suggesting that patients received enough anticopper therapy to prevent damage from copper toxicity but an adequate amount of copper for proper growth and development.

With regard to the pediatric dosage of zinc, while data was strong in children above 10 years of age, ${ }^{43}$ the possibility of overtreatment remains a concern for those less than 5 years of age. It remains an unresolved issue as to how early treatment should be started in pediatric Wilson's disease patients whose diagnosis is made very early in life. With evidence showing patients can begin to have hepatic damage as early as 3-4 years, ${ }^{88}$ Brewer et al suggested treating patients prophylactically once they are diagnosed, although probably not during the first year of life. ${ }^{43}$

Monitoring for overtreatment is especially important for pediatric patients because copper is required for proper growth and development. ${ }^{89}$ In very young children, mental development may be affected by copper deficiency, and in all children, proper growth and development require an adequate amount of copper. Bones and connective tissues are especially vulnerable to an inadequate supply of copper. ${ }^{89}$ All children with Wilson's disease must be receiving enough anticopper therapy to prevent damage from copper toxicity, but given the importance of adequate copper for growth and development, they must be carefully monitored to avoid overtreatment. The best monitoring tool remains following urine copper level to maintain it a little above the upper limit of normal ( $50 \mu \mathrm{g} / 24$ hours) or in the high normal range (40 $50 \mu \mathrm{g} / 24$ hours). The first evidence of clinical copper deficiency is a hypochromic microcytic anemia and leukopenia.

\section{Treatment compliance and monitoring}

The goal of treatment monitoring is to confirm clinical and biochemical improvement, ensure compliance with 
therapy, and identify adverse effects. Ensuring compliance in the setting of lifelong treatment is vital for the overall treatment sucess of Wilson's disease. The most difficult period to ensure compliance is in adolescence. Twentyfour-hour urinary copper excretion while on medication reflects overall exchangeable copper and is helpful for monitoring compliance. ${ }^{59}$ Patients taking D-penicillamine or trientine should have 24-hour urinary copper excretion values of $200-500 \mu \mathrm{g} /$ day (3-8 $\mu \mathrm{mol} /$ day); for patients on zinc, it should be no more than $75 \mu \mathrm{g} /$ day $(1.2 \mu \mathrm{mol} /$ day $) .{ }^{59}$ For patients on chelation therapy, elevated values of urine copper may suggest noncompliance while low values may indicate overtreatment, which is often accompanied by very low values of nonceruloplasmin-bound copper in the blood. For patients who are noncompliant with their chelation therapy or are taking subtherapeutic dosages, their 24-hour urine copper excretion may also show low values. But under this circumstance, their nonceruloplasmin-bound copper will be elevated instead, thus differentiating them from overtreatment. Compliance in patients taking zinc can be checked by measuring serum zinc or 24-hour urinary zinc excretion, which should be of the order of $2 \mathrm{mg} / 24$ hours. ${ }^{59}$ While interpreting the 24-hour urinary copper or zinc levels may help with monitoring compliance, the noncompliant patients would usually be noncompliant with their 24-hour urine collection rendering this a useless monitoring tool for them.

In addition to urinary monitoring, laboratory testing should also include liver biochemistries with tests of hepatic synthetic function and indices of copper metabolism (serum copper and ceruloplasmin). As mentioned above, serum nonceruloplasmin-bound copper is considered one of the best guides for treatment efficacy. Total blood count should be monitored in all patients on chelators for potential cytopenia side effect. Neutropenia and anemia may also be present in the overtreated patients as well.

\section{Conclusion}

It is beyond doubt that zinc is a beneficial treatment modality and has become an irreplaceable addition to the list of available therapeutic agents for Wilson's disease. Zinc, whether used alone or in combination with chelating agents, has been used widely and successfully over the last few decades to the benefit of numerous Wilson's disease patients. The relative safety and freedom from major side effects are its attributes.
Yet zinc is by no means faultless. The fact that it has to be taken three times a day and separate from meals to be effective challenges most patients' compliance. Also with over five decades of cumulative experience on its usage in various clinical settings, it has become clear that zinc is not the universal drug of choice for every Wilson's disease patient. Zinc's primary role remains in the treatment of presymptomatic/asymptomatic, pediatric, and pregnant patients, some neurologically affected as well as the stable patients who are in their maintenance phase of treatment. For the symptomatic patients, zinc may not be the best treatment option. With the potential risk of hepatic deterioration, the use of zinc monotherapy in treating symptomatic hepatic patients remains controversial. According to the current American and European Wilson's disease treatment guidelines, ${ }^{27,59} \mathrm{zinc}$ is not the recommended first-line therapeutic agent for symptomatic patients. Chelating agents are the drug of choice for symptomatic patients.

While zinc may not be efficacious for every Wilson's disease patient, seldom was it mentioned that zinc has toxic or harmful effects. ${ }^{90}$ This issue of potential toxicity was addressed in a recent editorial by Roberts titled Zinc toxicity: From 'No, Never' to 'Hardly Ever' - zinc can be toxic when it accumulates in cells beyond what is needed for normal cellular function. ${ }^{91}$

While most existing data on zinc comes from uncontrolled studies, what are needed are large-scale, multicenter, prospective, randomized, controlled, comparative trials to delineate clearly its role either as a single agent or in combination with other therapeutic agents for different clinical settings and at the same time to address the issue of potential toxicity.

Before the availability of results from large scale clinical trials addressing the above issues, it remains that careful choice of the suitable Wilson's disease patients to be treated with zinc and close monitoring of disease progress in all treated patients are the most important step towards optimizing long-term treatment outcome. Despite clinical stability, all treated Wilson's disease patients need to have their treatment monitored and closely followed up for the development of new neurologic or hepatic symptoms, and have regular assessment of liver function tests and urinary copper excretion to detect signs of inadequate response to treatment, possible overtreatment, or even potential long-term toxicity despite years of unchanged therapy. 


\section{Disclosure}

The authors report no conflicts of interest in this work.

\section{References}

1. Wilson SAK, Progressive lenticular degeneration: a familial nervousdisease associated with cirrhosis of the liver. Brain. 1912;34:20;V509.

2. Shah AB, Chernov I, Zhang HT, et al. Identification and analysis of mutations in the Wilson disease gene (ATP7B): population frequencies, genotype-phenotype correlation, and functional analyses. Am J Hum Genet. 1997;61(2):317-328.

3. Sternlieb I. Perspectives on Wilson's disease. Hepatology. 1990;12: 1234-1239.

4. Medici V, Trevisan CP, D'Inca R, et al. Diagnosis and management of Wilson's disease: results of a single center experience. J Clin Gastroenterol. 2006;40(10):936-941.

5. Czlonkowska A, Gajda J, Rodo M. Effects of long-term treatment in Wilson's disease with D-penicillamine and zinc sulphate. J Neurol. 1996;243(3):269-273.

6. Walshe JM. Penicillamine, a new oral therapy for Wilson's disease. Am J Med. 1956;21(4):487-495.

7. Yarze JC, Martin P, Munoz SJ, Friedman LS. Wilson's disease: current status. Am J Med. 1992;92(6):643-654.

8. Ala A, Walker AP, Ashkan K, Dooley JS, Schilsky ML. Wilson's disease. Lancet. 2007;369(9559):397-408.

9. Brewer GJ, Terry CA, Aisen AM, Hill GM. Worsening of neurologic syndrome in patients with Wilson's disease with initial penicillamine therapy. Arch Neurol. 1987;44(5):490-493.

10. Walshe JM. Copper chelation in patients with Wilson's disease. A comparison of penicillamine and triethylene tetramine dihydrochloride. QJ Med. 1973;42(167):441-452.

11. Sternlieb I, Scheinberg IH. Prevention of Wilson's disease in asymptomatic patients. $N$ Engl J Med. 1968;278(7):352-359.

12. Becuwe C, Dalle S, Ronger-Savle S, et al. Elastosis perforans serpiginosa associated with pseudo-pseudoxanthoma elasticum during treatment of Wilson's disease with penicillamine. Dermatology. 2005; 210(1):60-63.

13. Gibbs K, Walshe JM. Penicillamine and pyridoxine requirements in man. Lancet. 1966;1(7430):175-179.

14. Walshe JM, Yealland M. Chelation treatment of neurological Wilson's disease. Q J Med. 1993;86(3):197-204.

15. Schilsky ML. Treatment of Wilson's disease: what are the relative roles of penicillamine, trientine, and zinc supplementation? Curr Gastroenterol Rep. 2001;3(1):54-59.

16. Brewer GJ. Penicillamine should not be used as initial therapy in Wilson's disease. Mov Disord. 1999;14(4):551-554.

17. Walshe JM. Management of penicillamine nephropathy in Wilson's disease: a new chelating agent. Lancet. 1969;2(7635):1401-1402.

18. Sarkar B, Sass-Kortsak A, Clarke R, Laurie SH, Wei P. A comparative study of in vitro and in vivo interaction of D-penicillamine and triethylenetetramine with copper. Proc R Soc Med. 1977;70(Suppl 3): 13-18.

19. Ferenci P. Review article: diagnosis and current therapy of Wilson's disease. Aliment Pharmacol Ther. 2004;19(2):157-165.

20. Walshe JM. The management of Wilson's disease with trienthylene tetramine 2HC1 (Trien 2HC1). Prog Clin Biol Res. 1979;34: 271-280.

21. Scheinberg IH, Jaffe ME, Sternlieb I. The use of trientine in preventing the effects of interrupting penicillamine therapy in Wilson's disease. N Engl J Med. 1987;317(4):209-213.

22. Saito H, Watanabe K, Sahara M, Mochizuki R, Edo K, Ohyama Y. Triethylene-tetramine (trien) therapy for Wilson's disease. Tohoku $J$ Exp Med. 1991;164(1):29-35.

23. Santos Silva EE, Sarles J, Buts JP, Sokal EM. Successful medical treatment of severely decompensated Wilson disease. J Pediatr. 1996; 128(2):285-287.
24. Askari FK, Greenson J, Dick RD, Johnson VD, Brewer GJ. Treatment of Wilson's disease with zinc. XVIII. Initial treatment of the hepatic decompensation presentation with trientine and zinc. J Lab Clin Med. 2003;142(6):385-390.

25. Condamine L, Hermine O, Alvin P, Levine M, Rey C, Courtecuisse V. Acquired sideroblastic anaemia during treatment of Wilson's disease with triethylene tetramine dihydrochloride. $\mathrm{Br} J$ Haematol. 1993; 83(1):166-168.

26. Walshe JM. Treatment of Wilson's disease with trientine (triethylene tetramine) dihydrochloride. Lancet. 1982;1(8273):643-647.

27. European Association for Study of Liver. EASL Clinical Practice Guidelines: Wilson's disease. J Hepatol. 2012;56(3):671-685.

28. Gooneratne SR, Howell JM, Gawthorne JM. An investigation of the effects of intravenous administration of thiomolybdate on copper metabolism in chronic Cu-poisoned sheep. Br J Nutr. 1981;46(3): 469-480.

29. Brewer GJ, Hedera P, Kluin KJ, et al. Treatment of Wilson disease with ammonium tetrathiomolybdate: III. Initial therapy in a total of 55 neurologically affected patients and follow-up with zinc therapy. Arch Neurol. 2003;60(3):379-385.

30. Brewer GJ, Askari F, Lorincz MT, et al. Treatment of Wilson disease with ammonium tetrathiomolybdate: IV. Comparison of tetrathiomolybdate and trientine in a double-blind study of treatment of the neurologic presentation of Wilson disease. Arch Neurol. 2006;63(4):521-527.

31. Brewer GJ, Askari F, Dick RB, et al. Treatment of Wilson's disease with tetrathiomolybdate: V. Control of free copper by tetrathiomolybdate and a comparison with trientine. Transl Res. 2009;154(2):70-77.

32. Karunajeewa H, Wall A, Metz J, Grigg A. Cytopenias secondary to copper depletion complicating ammonium tetrathiomolybdate therapy for Wilson's disease. Aust N Z J Med. 1998;28(2):215-216.

33. Medici V, Trevisan CP, Bigotto MA, et al. Adverse reaction after tetrathiomolybdate treatment for Wilson's disease: a case report. $M o v$ Disord. 2006;21(11):2030-2032.

34. Dick AT. Studies on the accumulation and storage of copper in crossbred sheep. Austr J Agric Res. 1954;5:511-544.

35. Schouwink G. De hepato-cerebral degeneratie (met een onderozoek van de zinkstofwisseling), academisch profschrift Amsterdam [in Dutch]. Amsterdam, Netherlands: University of Amsterdam; 1961.

36. Brewer GJ, Yuzbasiyan-Gurkan V, Young AB. Treatment of Wilson's disease. Semin Neurol. 1987;7(2):209-220.

37. Brewer GJ, Hill GM, Prasad AS, Cossack ZT, Rabbani P. Oral zinc therapy for Wilson's disease. Ann Intern Med. 1983;99(3):314-319.

38. Hill GM, Brewer GJ, Prasad AS, Hydrick CR, Hartmann DE. Treatment of Wilson's disease with zinc. I. Oral zinc therapy regimens. Hepatology. 1987;7(3):522-528.

39. Cousins RJ. Absorption, transport, and hepatic metabolism of copper and zinc: special reference to metallothionein and ceruloplasmin. Physiol Rev. 1985;65(2):238-309.

40. Schilsky ML, Blank RR, Czaja MJ, et al. Hepatocellular copper toxicity and its attenuation by zinc. J Clin Invest. 1989;84(5):1562-1568.

41. Brewer GJ. Novel therapeutic approaches to the treatment of Wilson's disease. Expert Opin Pharmacother. 2006;7(3):317-324.

42. Brewer GJ, Dick RD, Johnson VD, Brunberg JA, Kluin KJ, Fink JK. Treatment of Wilson's disease with zinc: XV long-term follow-up studies. J Lab Clin Med. 1998;132(4):264-278.

43. Brewer GJ, Dick RD, Johnson VD, Fink JK, Kluin KJ, Daniels S. Treatment of Wilson's disease with zinc XVI: treatment during the pediatric years. J Lab Clin Med. 2001;137(3):191-198.

44. Brewer GJ, Johnson VD, Dick RD, Hedera P, Fink JK, Kluin KJ. Treatment of Wilson's disease with zinc. XVII: treatment during pregnancy. Hepatology. 2000;31(2):364-370.

45. Brewer GJ, Askari FK. Wilson's disease: clinical management and therapy. J Hepatol. 2005;42(Suppl 1):S13-S21.

46. Brewer GJ, Yuzbasiyan-Gurkan V, Lee DY, Appelman H. Treatment of Wilson's disease with zinc. VI. Initial treatment studies. J Lab Clin Med. 1989;114(6):633-638. 
47. Brewer GJ, Dick RD, Yuzbasiyan-Gurkan V, Johnson V, Wang Y. Treatment of Wilson's disease with zinc. XIII: therapy with zinc in presymptomatic patients from the time of diagnosis. J Lab Clin Med. 1994;123(6):849-858.

48. Brewer GJ, Yuzbasiyan-Gurkan V. Wilson disease. Medicine (Baltimore). 1992;71(3):139-164.

49. Brewer GJ, Hill GM, Dick RD, et al. Treatment of Wilson's disease with zinc: III. Prevention of reaccumulation of hepatic copper. J Lab Clin Med. 1987;109(5):526-531.

50. Brewer GJ, Hill G, Prasad A, Dick R. The treatment of Wilson's disease with zinc. IV. Efficacy monitoring using urine and plasma copper. Proc Soc Exp Biol Med. 1987;184(4):446-455.

51. Yuzbasiyan-Gurkan V, Grider A, Nostrant T, Cousins RJ, Brewer GJ. Treatment of Wilson's disease with zinc: X. Intestinal metallothionein induction. J Lab Clin Med. 1992;120(3):380-386.

52. Faa G, Nurchi V, Demelia L, et al. Uneven hepatic copper distribution in Wilson's disease. J Hepatol. 1995;22(3):303-308.

53. Hoogenraad TU, van Hattum J, van den Hamer CJ. Management of Wilson's disease with zinc sulphate. Experience in a series of 27 patients. J Neurol Sci. 1987;77(2-3):137-146.

54. Marcellini M, Di Ciommo V, Callea F, et al. Treatment of Wilson's disease with zinc from the time of diagnosis in pediatric patients: a single-hospital, 10-year follow-up study. J Lab Clin Med. 2005;145(3): 139-143.

55. Lee VD, Northup PG, Berg CL. Resolution of decompensated cirrhosis from Wilson's disease with zinc monotherapy: a potential therapeutic option? Clin Gastroenterol Hepatol. 2006;4(8):1069-1071.

56. Hoogenraad TU, van den Hamer CJ, Koevoet R, Korver EG. Oral zinc in Wilson's disease. Lancet. 1978;2(8102):1262.

57. Hoogenraad TU, Koevoet R, de Ruyter Korver EG. Oral zinc sulphate as long-term treatment in Wilson's disease (hepatolenticular degeneration). Eur Neurol. 1979;18(3):205-211.

58. Hoogenraad TU. Paradigm shift in treatment of Wilson's disease: zinc therapy now treatment of choice. Brain Dev. 2006;28(3): 141-146.

59. Roberts EA, Schilsky ML; American Association for Study of Liver Diseases. Diagnosis and treatment of Wilson disease: an update. Hepatology. 2008;47(6):2089-2111.

60. Pecoud A, Donzel P, Schelling JL. Effect of foodstuffs on the absorption of zinc sulfate. Clin Pharmacol Ther. 1975;17(4):469-474.

61. Walshe JM, Munro NA. Zinc-induced deterioration in Wilson's disease aborted by treatment with penicillamine, dimercaprol, and a novel zero copper diet. Arch Neurol. 1995;52(1):10-11.

62. Lang CJ, Rabas-Kolominsky P, Engelhardt A, Kobras G, Konig HJ. Fatal deterioration of Wilson's disease after institution of oral zinc therapy. Arch Neurol. 1993;50(10):1007-1008.

63. Brewer GJ, Yuzbasiyan-Gurkan V, Johnson V. Treatment of Wilson's disease with zinc. IX: Response of serum lipids. J Lab Clin Med. 1991; 118(5):466-470.

64. Alexiou D, Hatzis T, Koutselinis A. Maintenance treatment of Wilson's disease with oral zinc. Apropos of a child treated for 4 years. Arch Fr Pediatr. 1985;42(6):447-449. French.

65. Weiss KH, Gotthardt DN, Klemm D, et al. Zinc monotherapy is not as effective as chelating agents in treatment of Wilson disease. Gastroenterology. 2011;140(4):1189-1198.

66. Linn FH, Houwen RH, van Hattum J, van der Kleij S, van Erpecum KJ. Long-term exclusive zinc monotherapy in symptomatic Wilson disease: experience in 17 patients. Hepatology. 2009;50(5):1442-1452.

67. Walshe JM. Diagnosis and treatment of presymptomatic Wilson's disease. Lancet. 1988;2(8608):435-437.

68. Dhawan A, Taylor RM, Cheeseman P, De Silva P, Katsiyiannakis L, Mieli-Vergani G. Wilson's disease in children: 37-year experience and revised King's score for liver transplantation. Liver Transpl. 2005; 11(4):441-448.
69. Sokol RJ, Francis PD, Gold SH, Ford DM, Lum GM, Ambruso DR. Orthotopic liver transplantation for acute fulminant Wilson disease. J Pediatr. 1985;107(4):549-552.

70. Nazer H, Ede RJ, Mowat AP, Williams R. Wilson's disease: clinical presentation and use of prognostic index. Gut. 1986;27(11): 1377-1381.

71. Petrasek J, Jirsa M, Sperl J, et al. Revised King's College score for liver transplantation in adult patients with Wilson's disease. Liver Transpl. 2007;13(1):55-61.

72. Arnon R, Calderon JF, Schilsky M, Emre S, Shneider BL. Wilson disease in children: serum aminotransferases and urinary copper on triethylene tetramine dihydrochloride (trientine) treatment. J Pediatr Gastroenterol Nutr. 2007;44(5):596-602.

73. Shimono N, Ishibashi H, Ikematsu H, et al. Fulminant hepatic failure during perinatal period in a pregnant woman with Wilson's disease. Gastroenterol Jpn. 1991;26(1):69-73.

74. Morimoto I, Ninomiya H, Komatsu K, Satho M. Pregnancy and penicillamine treatment in a patient with Wilson's disease. Jpn J Med. 1986;25(1):59-62.

75. Dupont P, Irion O, Beguin F. Pregnancy in a patient with treated Wilson's disease: a case report. Am J Obstet Gynecol. 1990;163(5 Pt 1): 1527-1528.

76. Soong YK, Huang HY, Huang CC, Chu NS. Successful pregnancy after D-penicillamine therapy in a patient with Wilson's disease. J Formos Med Assoc. 1991;90(7):693-696.

77. Devesa R, Alvarez A, de las Heras G, Ramon de Miguel J. Wilson's disease treated with trientine during pregnancy. J Pediatr Gastroenterol Nutr. 1995;20(1):102-103.

78. Lao TT, Chin RK, Cockram CS, Leung NW. Pregnancy in a woman with Wilson's disease treated with zinc. Asia Oceania J Obstet Gynaecol. 1988;14(2):167-169.

79. Endres W. D-penicillamine in pregnancy - to ban or not to ban? Klin Wochenschr. 1981;59(11):535-537.

80. Biller J, Swiontoniowski M, Brazis PW. Successful pregnancy in Wilson's disease: a case report and review of the literature. Eur Neurol. 1985;24(5):306-309.

81. Hartard C, Kunze K. Pregnancy in a patient with Wilson's disease treated with D-penicillamine and zinc sulfate. A case report and review of the literature. Eur Neurol. 1994;34(6):337-340.

82. Nunns D, Hawthorne B, Goulding P, Maresh M. Wilson's disease in pregnancy. Eur J Obstet Gynecol Reprod Biol. 1995;62(1):141-143.

83. Sternlieb I. Wilson's disease and pregnancy. Hepatology. 2000;31(2): 531-532.

84. Keen CL, Mark-Savage P, Lonnerdal B, Hurley LS. Teratogenic effects of D-penicillamine in rats: relation to copper deficiency. Drug Nutr Interact. 1983;2(1):17-34.

85. Tanaka H, Yamanouchi M, Imai S, Hayashi Y. Low copper and brain abnormalities in fetus from triethylene tetramine dihydrochloridetreated pregnant mouse. J Nutr Sci Vitaminol (Tokyo). 1992;38(6): 545-554.

86. Solomon L, Abrams G, Dinner M, Berman L. Neonatal abnormalities associated with D-penicillamine treatment during pregnancy. $N$ Engl J Med.1997;296(1):54-55.

87. Kannan S, Dick RB, Johnson V, Brewer GJ, Effect of zinc treatment for Wilson's disease on zinc concentration in breast milk (abstract). JTrace Elem Exp Med. 2001;14:283.

88. Scheinberg, I, Sternlieb I. Wilson's Disease. Major Probl Intern Med. 1984;23:1-24.

89. Danks DM. Copper deficiency in humans. Annu Rev Nutr. 1988;8: 235-257.

90. Plum LM, Rink L, Haase H. The essential toxin: impact of zinc on human health. Int J Environ Res Public Health. 2010;7(4):1342-1365.

91. Roberts EA. Zinc toxicity: from "no, never" to "hardly ever." Gastroenterology. 2011;140(4):1132-1135. 


\section{Publish your work in this journal}

Orphan Drugs: Research and Reviews is an international, peer-reviewed, open access journal publishing original research, reports, reviews and commentaries on all areas of the design and development of orphan drugs for the treatment of rare diseases through to clinical applications Clinical outcomes, patient safety, and programs for the development and

Submit your manuscript here: http://www.dovepress.com/orphan-drugs-research-and-reviews-journ effective, safe, and sustained use of medicines will be a feature of the journal. The manuscript management system is completely online and includes a very quick and fair peer-review system, which is all easy to use. Visit http://www.dovepress.com/testimonials.php to read real quotes from published authors. 